\title{
Alterations in Resting State Functional Connectivity link Mindfulness Meditation with Reduced Interleukin-6: A Randomized Controlled Trial
}

\author{
In press, Biological Psychiatry
}

J. David Creswell, $\mathrm{PhD}^{1 \S}$, Adrienne A. Taren, $\mathrm{MD}^{2}$, Emily K. Lindsay, $\mathrm{MA}^{1}$, Carol M. Greco, $\mathrm{PhD}^{3}$, Peter J. Gianaros, $\mathrm{PhD}^{4}$, A pril Fairgrieve, $\mathrm{BS}^{1}$, Anna L. Marsland, $\mathrm{PhD}^{4}$, Kirk Warren Brown, $\mathrm{PhD}^{5}$, Baldwin M. Way, $\mathrm{PhD}^{6}$, Rhonda K. Rosen, $\mathrm{LCSW}^{4}$, Jennifer L. Ferris, $\mathrm{MA}^{1}$

${ }^{1}$ Department of Psychology and Center for the Neural Basis of Cognition, Carnegie Mellon University, 5000 Forbes Ave, Pittsburgh, PA, 15213

${ }^{2}$ Department of Neuroscience and Center for the Neural Basis of Cognition, University of Pittsburgh, A210 Langley Hall, Pittsburgh, PA, 15260

${ }^{3}$ Department of Psychiatry, University of Pittsburgh, 580 S. Aiken Ave, Pittsburgh, PA, 15232

${ }^{4}$ Department of Psychology and Center for the Neural Basis of Cognition, University of Pittsburgh, 210 South Bouquet St, Pittsburgh, PA, 15260

${ }^{5}$ Department of Psychology, Virginia Commonwealth University, 806 W Franklin St, Richmond, VA, 23284

${ }^{6}$ Department of Psychology, Ohio State University, 1827 Neil Ave, Columbus, OH, 43210

${ }^{\S}$ Corresponding Author: J. David Creswell, Associate Professor in Psychology and Center for the Neural Basis of Cognition, Carnegie Mellon University, 5000 Forbes Ave, Pittsburgh, PA, 15213, creswell@cmu.edu. (phone: 412-268-9182)

Keywords: mindfulness meditation; functional connectivity; IL-6; unemployment; fMRI; stress 


\begin{abstract}
Background: Mindfulness meditation training interventions have been shown to improve markers of health, but the underlying neurobiological mechanisms are not known. Building on initial cross-sectional research showing that mindfulness meditation may increase default mode network (DMN) resting state functional connectivity (rsFC) with regions important in top-down executive control (dorsolateral prefrontal cortex, dlPFC), here we test whether mindfulness meditation training increases DMN-dlPFC rsFC, and whether these rsFC alterations prospectively explain improvements in interleukin-6 (IL6 ) in a randomized controlled trial.
\end{abstract}

Method: Stressed job-seeking unemployed community adults $(\mathrm{N}=35)$ were randomized to either a 3-day intensive residential mindfulness meditation or relaxation training program. Participants completed a five-minute resting state scan before and after the intervention program. Participants also provided blood samples at pre-intervention and at 4-month follow-up, which were assayed for circulating IL-6, a biomarker of systemic inflammation.

Results: We tested for alterations in DMN rsFC using a posterior cingulate cortex (PCC) seed-based analysis, and found that mindfulness meditation training, and not relaxation training, increased PCC rsFC with left dlPFC ( $p<.05$, corrected). These pre-post training alterations in PCC-dlPFC rsFC statistically mediated mindfulness meditation training improvements in IL-6 at 4-month follow-up. Specifically, these alterations in rsFC statistically explained $30 \%$ of the overall mindfulness meditation training effects on IL-6 at follow-up.

Conclusions: These findings provide the first evidence that mindfulness meditation training functionally couples the DMN with a region known to be important in top-down executive control at rest (left dlPFC), which in turn is associated with improvements in a marker of inflammatory disease risk.

Abstract word count: 249

Trial Registration: The RCT is registered on clinicaltrials.gov (\#NCT01628809) 


\section{Alterations in Resting State Functional Connectivity link Mindfulness Meditation with Reduced Interleukin-6: A Randomized Controlled Trial}

Mindfulness meditation training programs, which train receptive attention and awareness to one's present moment experience, have been shown to improve a broad range of stress-related psychiatric and physical health outcomes in initial randomized controlled trials (e.g., depression relapse, anxiety, HIV-progression) (1-7). For example, recent well-controlled studies indicate that mindfulness meditation training may reduce markers of inflammation (C Reactive Protein, Interleukin-6 (IL-6), neurogenic inflammation) in stressed individuals (8-11). However, little is known about the neural mechanisms underlying the effects of mindfulness training on health among these individuals $(12 ; 13)$.

One possibility is that mindfulness meditation training alters resting state functional connectivity (rsFC) of brain networks implicated in mind wandering (the Default Mode Network, DMN) and executive control (the Executive Control Network, EC), which in turn improves emotion regulation, stress resilience, and stress-related health outcomes in at-risk patient populations $(1 ; 14-16)$. Two lines of research support this hypothesis. First, a cross-sectional study $(\mathrm{N}=25)$ showed that advanced mindfulness meditation practitioners had increased functional connectivity of a key hub in the default mode network (DMN) (i.e., posterior cingulate cortex) with regions considered to be important in top down executive control (EC) (dorsolateral prefrontal cortex, dorsal $\mathrm{ACC}$ ), both at rest and during a guided mindfulness meditation practice (17). This coupling of one's DMN at rest with regions of the EC network may be important for emotion regulation and stress resilience effects, as greater activation and functional 
connectivity of EC regions, such as the dlPFC, is associated with reduced pain, negative affect, and stress (18-21). A second line of research demonstrates initial links between alterations in DMN rsFC and psychiatric (e.g., Alzheimer's Disease, schizophrenia) (22; 23 ) and physical (e.g., obesity, diabetes) $(24 ; 25)$ health risks; for example, there is reduced rsFC of the posterior cingulate cortex and the dlPFC observed in schizophrenia patients relative to matched controls (26).

Here we provide the first experimental test of whether an intensive 3-day mindfulness meditation training intervention (relative to a relaxation training intervention) alters DMN connectivity and circulating IL-6 in a high stress unemployed job-seeking community sample. IL-6 is an established clinical health biomarker that is elevated in high stress populations $(27 ; 28)$ and is associated with elevated cardiovascular disease and mortality risk (29-31). Moreover, unemployment is a well-known chronic stressor that can foster a loss of control, helplessness, and financial setbacks (32) — and unemployment is associated with elevated inflammation (33). Building on initial crosssectional evidence (17), we hypothesized that mindfulness meditation training would increase rsFC between the DMN and regions implicated in attention and executive control (dlPFC and dACC). Moreover, we tested whether mindfulness meditation training (relative to relaxation training) decreased circulating IL-6 at 4-month follow up, and whether pre-post intervention increases in DMN-dlPFC rsFC mediated IL-6 improvements at 4-month follow-up.

\section{Method and Materials}

\section{Participants}


Thirty-five right-handed unemployed job-seeking community adults participated (see Table S1 for inclusion/exclusion study criteria) (see Figure S1 for Consort flowchart). Participants had moderate to high levels of job-seeking stress over the past month, scoring $>5$ on an adapted 4-item Perceived Stress Scale (34) $(M=9.60, S D=2.35$; for job-seeking stress measure see Table S1). After complete description of the study to the participants, written informed consent was obtained.

\section{Procedure}

Beginning four weeks before the 3-day training intervention, participants completed a baseline neuroimaging session, which included a 5-minute resting state scan where they passively viewed a fixation cross. After neuroimaging, participants were invited to a nearby residential retreat center where they provided a blood sample (for measurement of circulating IL-6) and were then randomized (via a random number generator by the study PI) to either a 3-day intensive mindfulness meditation training $(\mathrm{N}=18)$ or a matched 3-day relaxation residential retreat intervention $(\mathrm{N}=17)$. Posttreatment study personnel were blind to participant study condition (including personnel running the post-treatment MRI session and MRI data preprocessing). Participants returned for a neuroimaging assessment within two weeks of completing the 3-day intervention and completed an identical scanning procedure as at baseline (participants verbally confirmed they did not engage in meditation or relaxation activities during the resting state scan at both time points). At 4-month follow-up, participants were invited back to the retreat center where they provided a blood sample and completed a measurement battery. The measures described in this report are a subset of measures collected in this trial (see Supplementary Text). 


\section{Interventions}

We developed a 3-day residential mindfulness meditation retreat format from activities used in the Mindfulness-Based Stress Reduction (MBSR) program (35), called Health Enhancement through Mindfulness (HEM). Delivery of the HEM program in a structured residential retreat format improves compliance with training and reduces treatment attrition; greater experimental control is also afforded by offering a parallel matched relaxation training retreat (in a separate wing of the retreat center). Briefly, the HEM program consists of mindfulness training through body scan awareness exercises, sitting and walking meditations, mindful eating, mindful stretching, and discussion. We developed a structurally matched Health Enhancement through Relaxation (HER) program that included similar behavioral training activities (e.g., walking, stretching, and didactics) as HEM, but emphasized participation in these activities in a restful rather than a mindful way. The use of a structurally-matched active comparison group was designed to control for non-mindfulness specific factors such as positive treatment expectancies, group support, teacher attention, physical activity, and mental engagement. An hour-byhour outline of interventions is provided in Table S4.

\section{Neuroimaging Measures}

Image Acquisition and Preprocessing. Structural and functional images were acquired on a Siemens Verio 3T scanner using a 32-channel head coil. High-resolution T1-weighted gradient-echo images were acquired $(\mathrm{TR}=1800 \mathrm{~ms}$, $\mathrm{TE}=2.22 \mathrm{~ms}$, flip angle $=9^{\circ}$, matrix size $=256 \times 256$, number of slices $=256, F O V=205 \mathrm{~mm}, 0.8 \mathrm{~mm}$ slices , GRAPPA acceleration factor $P E=2$, voxel size $=0.8 \times 0.8 \times 0.8 \mathrm{~mm}$ ). Next, four functional echo-planar imaging runs were acquired, including a 300 second resting state scan 
$\left(\mathrm{TR}=2000 \mathrm{~ms}, \mathrm{TE}=30 \mathrm{~ms}\right.$, flip angle $=79^{\circ}$, matrix size $=64 \times 64$, number of slices $=36, \mathrm{FOV}=$ 205mm, $3.2 \mathrm{~mm}$ thick slices EPI with rate 2 GRAPPA, voxel size $=3.2 \mathrm{~mm} \times 3.2 \mathrm{~mm} \times 3.2 \mathrm{~mm})$.

Three participants were excluded from fMRI data analyses due to neuroimaging session problems (at the baseline appointment: 1 participant reported sleeping, 1 had poor coverage, and 1 did not understand directions; at the post-treatment appointment: 1 participant reported sleeping, 1 did not understand directions, and 1 had poor coverage). Functional BOLD data were processed using SPM8 (Welcome Department of Cognitive Neurology, London, UK; implemented by MATLAB, MathWorks, Inc., Natick, MA, USA). Functional images were first realigned to the mean image of the first run and then smoothed with a 4mm FWHM Gaussian kernel. Data were then submitted to motion correction using the Art Repair utility (36), an interpolation-based motion correction program. The functional data was then normalized to the standard Montreal Neurological Institute (MNI) T1 template. Finally, the images were smoothed with a 7mm FWHM kernel, resulting in an overall FWHM smoothing of $8 \mathrm{~mm}(36)$.

\section{IL-6 and Psychosocial Measures}

IL-6. Blood samples were collected (between the hours of 10am-noon) and processed (then frozen) in batch at baseline and at 4-month follow-up by technicians blinded to treatment conditions. IL-6 levels were determined from plasma in duplicate by high sensitivity quantitative sandwich enzyme immunoassay kit (R\& D Systems, Minneapolis, MN) run according to manufacturer's directions. Two participants had insufficient samples for IL-6 determination, and were excluded. 
Psychosocial Measures. In order to evaluate whether the relaxation retreat program produced equivalent positive beliefs about its value (a placebo control) compared to the mindfulness retreat program, participants completed a 6-item measure of perceived positive treatment benefits at the conclusion of the 3-day retreat program using an adapted version of the Credibility/Expectancy Questionnaire (37) (study $\alpha=.87$, sample item: "At this point, how much do you really feel that this therapy will help you reduce your stress symptoms?" $1=$ not at all to $9=$ very much). Re-employment status was assessed at 4-month follow-up; participants indicated whether they were unemployed, defined as having no job for more than 20 hours per week in the 4-month post-treatment period.

\section{Data Analysis}

Resting State Functional Connectivity Analysis. PCC-seeded resting state BOLD fMRI images were generated in the CONN toolbox, following the recommended CONN analysis procedures (35). Specifically, CONN implements several additional processing and $1^{\text {st }}$ level analysis routines prior to $\mathrm{rsFC}$ analysis: CONN estimates an orthogonal time series using principal component analysis of the BOLD time series in each noise ROI (subject-specific white matter and csf masks). Structural MPRAGE images were segmented to define gray matter, white matter, and cerebrospinal fluid areas. BOLD signal from the subject-specific white matter and CSF masks, motion parameters (six dimensions), and the effect of rest (an average across the session) were used as regressors to account for further temporal confounding factors. CONN uses a component-based noise reduction (CompCor) that avoids regression of the global signal. A covariate for each subject's head motion was entered at the first level. A band-pass 
filter of $0.008-0.09 \mathrm{~Hz}$ was used. A hemodynamic response function was used to downweight the initial scans within each resting state block to minimize potential ramping effects.

The PCC seed was anatomically defined using the Talaraich deamon database in the Wake Forest University (WFU) Pickatlas (38) centered on MNI: $-4,-50,40$. Seeded first-level maps in CONN were then submitted to a second-level full factorial analysis in SPM8 with two factors specified, time and group. To test study predictions in the brain, we specified a time-by-group spreading interaction contrast that tested for baseline to post-intervention increases in $\mathrm{rsFC}$ in the HEM program relative to no change in the HER program from baseline to post-intervention using contrast weights: [-1(pre,HEM), -1(pre,HER), 3(post, HEM), -1(post,HER)]. This $t$-contrast models the specific hypothesized differential group change from baseline to post-treatment. The strength of this approach (relative to testing for significant voxels using the more standard overall $F$-contrast, or just comparing the two groups at post-treatment only) is that it tests the specific prediction the mindfulness meditation program increased rsFC from baseline to post-treatment compared to no change in the relaxation group (as opposed to other types of interaction patterns that might be significant with an $F$-contrast analysis). Note that this approach compares the mindfulness group at post-treatment to the average of the other cells in this $2 \mathrm{X} 2$ design, testing the spreading interaction prediction (and not other interaction patterns, e.g., crossover interactions). Furthermore, we then plotted the parameter estimates from this spreading interaction contrast to visually confirm the specific interaction pattern (see Figure $1 \mathrm{~b}$ and 1c). 
For purposes of testing rsFC with the PCC in this study, two ROI masks were created using the WFU Pickatlas AAL atlas (each with dilation of $1 \mathrm{~mm}$ ): the first mask consisted of the left and right anterior cingulate, and the second ROI mask consisted of the left and right middle frontal cortex (based on 17). Cluster-level correction for multiple comparisons was obtained using a Monte Carlo simulations in AlphaSim (National Institute of Mental Health, Bethesda, MD). AlphaSim was first run on the anterior cingulate AAL-defined mask, with significant clusters ( $p<.05$, corrected) defined as those involving $k>49$ contiguous voxels, each at $p<.005$. AlphaSim was then run on the middle frontal cortex AAL-defined ROI mask, with significant clusters ( $p<.05$, corrected) defined as those involving $k>82$ contiguous voxels, each at $p<.005$.

IL-6 and Head Motion Analysis. IL-6 values at baseline and 4-month follow-up were $\log$ transformed. Analyses adhered to intent-to-treat principles using mixed effect linear models (MLMs) conducted in SPSS 21.0 (IBM, Armonk, New York). All variables were modeled as fixed effects in models fit with a compound symmetric variancecovariance structure, using maximum likelihood estimation. These models included a condition factor (HEM vs. HER program), a time factor (baseline, 4-month follow-up), and their interaction, with $F$-statistics used to evaluate significant effects. All IL-6 MLMs included participant age as a covariate given the significant range in participant age in this sample (22-54 years old), as age is robustly associated with increasing IL-6 $(27 ; 39)$. To test whether there were condition (and time $\times$ condition) differences in fast head motion (defined as TR-TR head motion greater than $.25 \mathrm{~mm}$ or .25 degrees in any plane), a hypothesis and condition-blind coder summed total high head motion TRs for each 
participant's baseline and post-treatment resting state scan, which was then tested in a MLM with total head motion as the outcome.

PCC Resting State Functional Connectivity Mediation Analysis. Statistical mediation analyses were conducted following recommended procedures for testing intervening variable effects, using MLMs (40; 41). Specifically, rsFC cluster-level parameter estimates were extracted from the SPM8 group-level analyses and tested as mediating variables in a series of MLMs. The MLMs consisted of (MLM \#1) testing a time $\times$ condition interaction effect on change in PCC rsFC (path a, see Figure 2); (MLM \#2) testing for a significant effect of PCC rsFC on change in IL-6 (path b), when the PCC rsFC variable (baseline, post-training) was entered simultaneously along with the condition, time, and time $\times$ condition interaction variables; and (MLM \#3) whether the original time $\times$ condition interactive effect on IL- 6 (path c) was no longer statistically significant when the PCC rsFC effect was entered as a simultaneous predictor variable (path c'). Statistical mediation was defined as present when: 1) there were significant intervening variable paths (paths a and $b$ ), and 2 ) when the original time $\times$ condition interaction on IL-6 (path c') was no longer significant when the change in rsFC variable was entered as a simultaneous predictor variable.

\section{Results}

Preliminary Analyses—Success of randomization and treatment program measures. There were no significant differences between the mindfulness (HEM) and relaxation (HER) groups on study baseline characteristics, indicating successful randomization (see Table 1). There were no significant group differences in fast head motion during the resting state scan period $(F(1,35)=.002, p=.97)$ and no differential fast 
head motion changes from baseline to the post-treatment fMRI resting state scan between groups $($ time $\times$ condition $F(1,34)=.001, p=.98)$. The relaxation training program was an effective placebo control; there were no significant group differences in perceived treatment benefits at the conclusion of the 3-day retreat (independent samples $t(31)=1.06$, $p=.30 ;$ HEM $M=38.76, S E=2.19$, HER $M=42.03, S E=2.13)$.

97\% of randomized participants completed the 3-day training programs and $97 \%$ were retained at the 4-month follow-up assessment (see Fig. S1 for CONSORT flowchart). These high retention rates may have reflected the high (and equivalent) treatment satisfaction reported by participants in both the mindfulness (HEM $M=4.15$, $S E=.18)$ and relaxation (HER $M=4.12, S E=.19)$ programs at follow-up (single item: "Would you recommend this program to other people you know?": $1=$ not at all to $5=\mathrm{a}$ great deal; independent samples $t(32)=.11, p=.91)$. Despite our efforts to encourage home practice after the 3-day retreats (along with sending participants home with customized compact discs containing guided condition-specific mindfulness and relaxation exercises), participants did not complete much formal practice in the 4-month follow-up period. HEM participants reported using their home practice CD an average of 1.24 times per week ( $\mathrm{SD}=1.28)$ over the last month (at the 4-month follow-up assessment), while HER participants reported using their home practice $\mathrm{CD} .38$ times per week $(\mathrm{SD}=.86)$ over the last month $(t(31)=2.27, p=.03)$. (We also did not collect measures of home practice in the day(s) following the retreat program leading up to the post-treatment fMRI session, a study limitation.)

\section{Primary Analyses-Alterations in DMN resting state functional connectivity.}

Consistent with predictions, there was a significant pre-post intervention increase in $\mathrm{rsFC}$ 
between the PCC (the DMN seed region) and left dIPFC (MNI: $-22,52,10 ; k=111$; $Z=3.44, p<.05$, corrected) in the mindfulness meditation training group relative to the relaxation training control group. As shown in Figure 1, there was no coupling of PCC with the left dlPFC (panel B) at baseline in both the mindfulness and relaxation groups, but at post-treatment the mindfulness (but not relaxation) group showed positive coupling of PCC and left dIPFC. Although the clusters did not survive multiple comparison correction, a homologue region of right dlPFC showed a similar effect (MNI: 26,44,34; $k=24 ; Z=3.22$; see Figure 1 panel C), along with another cluster in left dlPFC (MNI: $30,42,38 ; k=77 ; Z=3.11)$. Contrary to predictions, mindfulness meditation training did not significantly alter rsFC of the PCC with dACC. We also observed no alterations in intraDMN rsFC; specifically, mindfulness meditation training did not decouple the PCC with other DMN nodes (e.g., PCC with ventromedial PFC) (42). We provide exploratory time $\times$ condition interaction results for PCC rsFC across the whole brain in Tables $\mathrm{S} 2$ and $\mathrm{S} 3$ (thresholded at uncorrected $p<.005, k>50$ voxels).

Circulating IL-6. There were no significant baseline differences in log transformed IL-6 (or raw IL-6; see Table 1) between the mindfulness meditation and relaxation training groups $(t(28)=1.04, p=.31)$. However, mindfulness meditation training, relative to relaxation training, reduced circulating levels of IL-6 at 4-month follow-up. A mixed effect linear model (controlling for participant age) indicated that mindfulness meditation training significantly reduced circulating log-transformed IL-6 from baseline $(M=.13, S E=.07)$ to 4 -month follow-up $(M=.08, S E=.08)$ compared to increases in the relaxation training group (baseline $M=-.06, S E=.08$; 4-month follow-up $M=.08, S E=.07)($ time $\times$ condition interaction $F(1,29)=4.14, p=.05, d=.71)($ see Table 2$)$. 
Changes in re-employment during the 4-month follow-up period could have explained these changes in IL-6, but this was not the case; there were equal rates of re-employment in the two groups at the 4-month follow-up assessment (48\% of participants in both groups were re-employed at 4-month follow-up).

Alterations in DMN rsFC mediate mindfulness meditation training improvements in $I L-6$. As shown in Figure 3, increases in pre-post intervention PCC-left dlPFC rsFC statistically mediated changes in circulating IL-6 from baseline to 4-month follow-up. Specifically, a mediation model indicated that the strength of the time $\times$ condition interaction effect on IL-6 (path c) was no longer significant when the change in the left dIPFC cluster (MNI:-22,52,10; $k=111)$ connectivity predictor variable was entered simultaneously in a mixed effect linear model (see path c' in Figure 2). Although the right dlPFC cluster did not survive multiple comparison correction (MNI: 26,44,34; $k=24)$, it also marginally significantly mediated the IL-6 effects (also shown in Figure 3). Mindfulness meditation training alterations in rsFC observed in the second left dIPFC cluster (MNI:-30,42,38) did not mediate IL-6 effects. These findings in Figure 2 indicate that change in PCC-dlPFC connectivity accounts for 30\% (left dlPFC MNI:-22,52,10) and 25\% (right dlPFC MNI:26,44,34) of the overall mindfulness meditation (vs relaxation training) effect on reductions in IL-6 at 4-month follow-up.

\section{Conclusions}

There has been considerable recent interest in characterizing resting state neural networks such as the DMN, and understanding their role in health and disease (23). We report that mindfulness meditation training (compared to relaxation training without a mindfulness component) increased rsFC between the DMN (PCC) and left dlPFC. These 
findings corroborate and experimentally extend cross-sectional findings in advanced mindfulness meditation practitioners (17), suggesting that mindfulness meditation training may couple one's resting state DMN with regions implicated in executive control (dIPFC). These findings were specific to coupling of the PCC with dIPFC, and not with dACC (cf. 17). Notably, some work has shown that dIPFC and dACC are involved with dissociable executive control and salience processing networks, respectively (43); furthermore, whereas increased dACC connectivity is associated with anxiety, increased dIPFC connectivity is associated with behavioral improvements in executive task performance (e.g., attention task switching) (43).

Although studies commonly report that the DMN is anti-correlated with regions in the executive control network $(44 ; 45)$, some studies indicate positive PCC-dlPFC coupling during self-focused and process-oriented mental simulations (45-47) and during guided mindfulness meditation practice (17). These findings suggest that a processoriented focus on the self during meditation may shift intra-network DMN rsFC toward inter-network connectivity, coupling DMN with regions in the executive control network. Notably, the present results show that these alterations in DMN-EC rsFC can be maintained in the weeks following brief, intensive mindfulness meditation training.

We also provide an initial indication in this $\mathrm{RCT}$ sample $(\mathrm{N}=35)$ that mindfulness meditation training reduces IL-6 from baseline to 4-month follow-up, compared to increases in IL-6 in the relaxation training control group. This finding suggests that mindfulness meditation training may decrease biomarkers of inflammatory disease risk in populations whom have elevated inflammation (such as stressed unemployed adults), although we note this was a small sample and this IL-6 finding should be treated with 
some caution. But like this study finding, several studies show that mindfulness meditation training interventions reduce markers of inflammation in stressed populations (8-11). Moreover, the present work shows that pre-post training changes in PCC-dlPFC rsFC mediate these effects on IL-6. Currently very little is known about top-down neural modulation of peripheral inflammation in humans, despite a large number of epidemiologic studies linking peripheral circulating pro-inflammatory cytokines with cardiovascular morbidity and all-cause mortality $(29-31 ; 48)$. Some initial studies in humans highlight reciprocal brain-peripheral inflammation links (49; 50), although the present study offers a novel top-down regulatory pathway for the modulation of circulating IL-6 in humans. Notably, studies have implicated activation and functional connectivity of dlPFC with improved executive control resources, and reduced pain, negative affect and stress $(18-21 ; 43)$. We speculate that mindfulness meditation training coupled the brain's DMN with regulatory areas of prefrontal cortex (dlPFC), which facilitated more effective emotion regulation and stress resilience in this high stress unemployed job-seeking sample, reducing circulating IL-6. Specifically, efferent projections from dlPFC might modulate medial PFC and subcortical cell groups known to trigger peripheral stress and inflammatory response cascades $(51 ; 52)$. A small experimental literature provides initial support for this neural stress-buffering account of mindfulness meditation training (14), although more research is needed to evaluate these stress reduction mediated pathways.

An important question going forward will be to evaluate whether these observed PCC-dlPFC rsFC changes reflect neuroplasticity in white matter connectivity after mindfulness meditation training. Several lines of evidence provide suggestive support: 
anatomic studies in primate models have shown that measures of $\mathrm{rsFC}$ have high correspondence to underlying white matter architecture (53), and there are established white matter tracts linking PCC with dlPFC (54). Notably, an initial experimental study demonstrates that even brief meditation training ( $\sim 11$ hours) fosters neuroplasticity by increasing white matter connectivity (as measured by fractional anisotropy) of the anterior corona radiata (55).

Unlike a previous study (17), mindfulness meditation training did not increase PCC-dACC rsFC in this sample. We speculate that one possibility for these divergent effects may be due to differences in study methodology. The previous study measured rsFC using 2-minute resting state periods at the beginning of each run, followed by 4.5 minute meditation practice periods (17). By contrast, the present study collected rsFC at the beginning of the fMRI session (immediately following the collection of the structural scans). Some neuroimaging evidence indicating that acute meditation practice activates the ACC (56; 57), and it may be that ACC activity during these 4.5 minute meditation practice periods had some residual carry-over into the rsFC scans in the previous study. Indeed, there is research showing that cognitive tasks have carry-over effects on PCCACC functional connectivity during subsequent rsFC periods (58). The present study design is less susceptible to potential task-based carry over effects, and provides an initial indication for non-task based PCC-dlPFC rsFC effects in the weeks following a 3-day mindfulness meditation training intervention.

\section{Conclusions}

Little is known about how behavioral interventions, such as mindfulness meditation training, can impact the brain and physical health. We provide the first well- 
controlled evidence that 3-days of mindfulness meditation training increases rsFC of the DMN with neural regions important in executive control (left dlPFC), and that these rsFC changes statistically mediate improvements in circulating levels of IL-6 at follow-up. 


\section{Acknowledgements and Financial Disclosures}

The authors declare no conflicts of interest. J.D. Creswell and A.A. Taren had full access to the data and take responsibility for the integrity of the data and the accuracy of the data analysis. We would like to thank the research assistants in the Health and Human Performance laboratory, the blood draw nurses (Karen Foley, Diana Ross) and lab technician (Katarina Krajina), the Sisters at Kearns Spirituality Center for hosting the retreats, and the Scientific Imaging and Brain Research (SIBR) center. We also thank Erica Julson, Laura Pacilio, and Shinzen Young for help and feedback.

The authors report no financial interests or potential conflicts of interest regarding this research. This research was supported by funding from the Pittsburgh Life Sciences Greenhouse Opportunity Fund, who played no role in the design and conduct of the study; collection management, analysis, and interpretation of the data; and preparation, review, or approval of the manuscript; and the decision to submit the manuscript for publication. 


\section{References}

1. Ludwig DS, Kabat-Zinn J (2008): Mindfulness in medicine. J Am Med Assoc. 300: $1350-1352$.

2. Brown KW, Ryan RM, Creswell JD (2007): Mindfulness: Theoretical foundations and evidence for its salutary effects. Psychol Inq. 18: 211-237.

3. Goyal M, Singh S, Sibinga EM, Gould NF, Rowland-Seymour A, Sharma R, et al. (2014): Meditation programs for psychological stress and well-being: a systematic review and meta-analysis. JAMA Intern Med. 174: 357-368.

4. Segal ZV, Bieling P, Young T, MacQueen G, Cooke R, Martin L, et al. (2010): Antidepressant monotherapy vs sequential pharmacotherapy and mindfulness-based cognitive therapy, or placebo, for relapse prophylaxis in recurrent depression. Arch Gen Psychiatry. 67: 1256.

5. Teasdale JD, Segal ZV, Mark J, Ridgeway VA, Soulsby JM, Lau MA (2000): Prevention of relapse/recurrence in major depression by mindfulness-based cognitive therapy. J Consult Clin Psychol. 68: 615-623.

6. Creswell JD, Myers HF, Cole SW, Irwin MR (2009): Mindfulness meditation training effects on CD4+ T lymphocytes in HIV-1 infected adults: A small randomized controlled trial. Brain Behav Immun. 23: 184-188.

7. Goldin PR, Gross JJ (2010): Effects of mindfulness-based stress reduction (MBSR) on emotion regulation in social anxiety disorder. Emotion. 10: 83-91.

8. Creswell JD, Irwin MR, Burklund LJ, Lieberman MD, Arevalo JMG, Ma J, et al. (2012): Mindfulness-Based Stress Reduction training reduces loneliness and 
pro-inflammatory gene expression in older adults: A small randomized controlled trial. Brain Behav Immun. 26: 1095-1101.

9. Malarkey WB, Jarjoura D, Klatt M (2013): Workplace based mindfulness practice and inflammation: A randomized trial. Brain Behav Immun. 27: 145-154.

10. Rosenkranz MA, Davidson RJ, MacCoon DG, Sheridan JF, Kalin NH, Lutz A (2013): A comparison of mindfulness-based stress reduction and an active control in modulation of neurogenic inflammation. Brain Behav Immun. 27C: 174-184.

11. Lengacher CA, Kip KE, Barta MK, Post-White J, Jacobsen P, Groer M, et al. (2012): A Pilot Study Evaluating the Effect of Mindfulness-Based Stress Reduction on Psychological Status, Physical Status, Salivary Cortisol, and Interleukin-6 Among Advanced-Stage Cancer Patients and Their Caregivers. J Holist Nurs. 30: 170-185.

12. Hölzel BK, Lazar SW, Gard T, Schuman-Olivier Z, Vago DR, Ott U (2011): How does mindfulness meditation work? Proposing mechanisms of action from a conceptual and neural perspective. Perspect Psychol Sci. 6: 537-559.

13. Tang Y-Y, Hölzel BK, Posner MI (2015): The neuroscience of mindfulness meditation. Nat Rev Neurosci. 16: 213-225.

14. Creswell JD, Lindsay EK (2014): How does mindfulness training affect health? A mindfulness stress buffering account. Curr Dir Psychol Sci. 23: 401-407.

15. Mrazek MD, Smallwood J, Schooler JW (2012): Mindfulness and mindwandering: Finding convergence through opposing constructs. Emotion. 12: $442-448$. 
16. Christoff K, Gordon AM, Smallwood J, Smith R, Schooler JW (2009): Experience sampling during fMRI reveals default network and executive system contributions to mind wandering. Proc Natl Acad Sci. 106: 8719-8724.

17. Brewer JA, Worhunsky PD, Gray JR, Tang Y-Y, Weber J, Kober H (2011): Meditation experience is associated with differences in default mode network activity and connectivity. Proc Natl Acad Sci. 108: 20254-20259.

18. Wager TD, Rilling JK, Smith EE, Sokolik A, Casey KL, Davidson RJ, et al. (2004): Placebo-Induced Changes in fMRI in the Anticipation and Experience of Pain. Science. 303: 1162-1167.

19. Lorenz J, Minoshima S, Casey KL (2003): Keeping pain out of mind: the role of the dorsolateral prefrontal cortex in pain modulation. Brain. 126: 10791091.

20. Goldin PR, McRae K, Ramel W, Gross JJ (2008): The Neural Bases of Emotion Regulation: Reappraisal and Suppression of Negative Emotion. Biol Psychiatry, Stress, Anxiety, and Post-Traumatic Stress Disorder. 63: 577-586.

21. Cisler JM, James GA, Tripathi S, Mletzko T, Heim C, Hu XP, et al. (2013):

Differential functional connectivity within an emotion regulation neural network among individuals resilient and susceptible to the depressogenic effects of early life stress. Psychol Med. 43: 507-518.

22. Greicius M (2008): Resting-state functional connectivity in neuropsychiatric disorders: Curr Opin Neurol. 24: 424-430. 
23. Anticevic A, Cole MW, Murray JD, Corlett PR, Wang X-J, Krystal JH (2012): The role of default network deactivation in cognition and disease. Trends Cogn Sci. 16: 584-592.

24. Tregellas JR, Wylie KP, Rojas DC, Tanabe J, Martin J, Kronberg E, et al. (2011): Altered Default Network Activity in Obesity. Obesity. 19: 2316-2321.

25. Musen G, Jacobson AM, Bolo NR, Simonson DC, Shenton ME, McCartney RL, et al. (2012): Resting-State Brain Functional Connectivity Is Altered in Type 2 Diabetes. Diabetes. 61: 2375-2379.

26. Zhou Y, Liang M, Jiang T, Tian L, Liu Y, Liu Z, et al. (2007): Functional dysconnectivity of the dorsolateral prefrontal cortex in first-episode schizophrenia using resting-state fMRI. Neurosci Lett. 417: 297-302.

27. Kiecolt-Glaser JK, Preacher KJ, MacCallum RC, Atkinson C, Malarkey WB, Glaser R (2003): Chronic stress and age-related increases in the proinflammatory cytokine IL-6. Proc Natl Acad Sci. 100: 9090-9095.

28. Steptoe A, Hamer M, Chida Y (2007): The effects of acute psychological stress on circulating inflammatory factors in humans: A review and meta-analysis. Brain Behav Immun. 21: 901-912.

29. Harris TB, Ferrucci L, Tracy RP, Corti MC, Wacholder S, Ettinger Jr WH, et al. (1999): Associations of elevated Interleukin-6 and C-Reactive protein levels with mortality in the elderly. Am J Med. 106: 506-512.

30. Pal M, Febbraio MA, Whitham M (2014): From cytokine to myokine: the emerging role of interleukin-6 in metabolic regulation. Immunol Cell Biol. 92: 331-339. 
31. Danesh J, Kaptoge S, Mann AG, Sarwar N, Wood A, Angleman SB, et al. (2008): Long-Term Interleukin-6 Levels and Subsequent Risk of Coronary Heart Disease: Two New Prospective Studies and a Systematic Review. PLoS Med. 5: e78.

32. Baum A, Fleming R, Reddy DM (1986): Unemployment stress: Loss of control, reactance and learned helplessness. Soc Sci Med. 22: 509-516.

33. Hintikka J, Lehto S, Niskanen L, Huotari A, Herzig K-H, Koivumaa-Honkanen H, et al. (2009): Unemployment and ill health: a connection through inflammation? BMC Public Health. 9: 410.

34. Warttig SL, Forshaw MJ, South J, White AK (2013): New, normative, Englishsample data for the Short Form Perceived Stress Scale (PSS-4). J Health Psychol. 18: 1617-1628.

35. Kabat-Zinn J (1990): Full catastrophe living: Using the wisdom of your body and mind to face stress, pain, and illness. New York, NY: Delta.

36. P. Mazaika, Whitfield-Gabrieli S, Reiss A (2007): Artifact repair for fMRI data from motion clinical subjects. Presented at the Organization for Human Brain Mapping Annual Conference.

37. Devilly GJ, Borkovec TD (2000): Psychometric properties of the credibility/expectancy questionnaire. J Behav Ther Exp Psychiatry. 31: 73-86.

38. Maldjian JA, Laurienti PJ, Kraft RA, Burdette JH (2003): An automated method for neuroanatomic and cytoarchitectonic atlas-based interrogation of fMRI data sets. Neuroimage. 19: 1233-1239. 
39. Wei J, Xu H, Davies JL, Hemmings GP (1992): Increase of plasma IL-6 concentration with age in healthy subjects. Life Sci. 51: 1953-1956.

40. MacKinnon DP, Lockwood CM, Hoffman JM, West SG, Sheets V (2002): A comparison of methods to test mediation and other intervening variable effects. Psychol Meth. 7: 83-104.

41. Baron RM, Kenny DA (1986): The moderator-mediator variable distinction in social psychological research: Conceptual, strategic, and statistical considerations. J Pers Soc Psychol. 51: 1173-1182.

42. Buckner RL, Andrews-Hanna JR, Schacter DL (2008): The Brain's Default Network. Ann N Y Acad Sci. 1124: 1-38.

43. Seeley WW, Menon V, Schatzberg AF, Keller J, Glover GH, Kenna H, et al. (2007): Dissociable Intrinsic Connectivity Networks for Salience Processing and Executive Control. J Neurosci. 27: 2349-2356.

44. Fox MD, Snyder AZ, Vincent JL, Corbetta M, Essen DCV, Raichle ME (2005): The human brain is intrinsically organized into dynamic, anticorrelated functional networks. Proc Natl Acad Sci U S A. 102: 9673-9678.

45. Spreng RN (2012): The Fallacy of a "Task-Negative" Network. Front Psychol. 3: 145.

46. Gerlach KD, Spreng RN, Madore KP, Schacter DL (2014): Future planning: default network activity couples with frontoparietal control network and rewardprocessing regions during process and outcome simulations. Soc Cogn Affect Neurosci. nsu001. 
47. Spreng RN, Stevens WD, Chamberlain JP, Gilmore AW, Schacter DL (2010): Default network activity, coupled with the frontoparietal control network, supports goal-directed cognition. NeuroImage. 53: 303-317.

48. Cesari M, Penninx BWJH, Newman AB, Kritchevsky SB, Nicklas BJ, Sutton-Tyrrell K, et al. (2003): Inflammatory markers and onset of cardiovascular events. Circulation. 108: 2317-2322.

49. Harrison NA, Brydon L, Walker C, Gray MA, Steptoe A, Critchley HD (2009): Inflammation Causes Mood Changes Through Alterations in Subgenual Cingulate Activity and Mesolimbic Connectivity. Biol Psychiatry. 66: 407-414.

50. Gianaros PJ, Marsland AL, Kuan DC-H, Schirda BL, Jennings JR, Sheu LK, et al. (2014): An Inflammatory Pathway Links Atherosclerotic Cardiovascular Disease Risk to Neural Activity Evoked by the Cognitive Regulation of Emotion. Biol Psychiatry, Mechanisms of Aging and Cognition. 75: 738-745.

51. Irwin MR, Cole SW (2011): Reciprocal regulation of the neural and innate immune systems. Nat Rev Immunol. 11: 625-632.

52. Jankord R, Zhang R, Flak JN, Solomon MB, Albertz J, Herman JP (2010): Stress activation of IL-6 neurons in the hypothalamus. Am J Physiol - Regul Integr Comp Physiol. 299: R343-R351.

53. Wang Z, Chen LM, Négyessy L, Friedman RM, Mishra A, Gore JC, Roe AW (2013): The Relationship of Anatomical and Functional Connectivity to Resting-State Connectivity in Primate Somatosensory Cortex. Neuron. 78: 1116-1126. 
54. Vogt BA, Rosene DL, Pandya DN (1979): Thalamic and Cortical Afferents Differentiate Anterior from Posterior Cingulate Cortex in the Monkey. Science, New Series. 204: 205-207.

55. Tang Y-Y, Lu Q, Geng X, Stein EA, Yang Y, Posner MI (2010): Short-term meditation induces white matter changes in the anterior cingulate. Proc Natl Acad Sci. 107: 15649-15652.

56. Zeidan F, Martucci KT, Kraft RA, Gordon NS, McHaffie JG, Coghill RC (2011): Brain mechanisms supporting the modulation of pain by mindfulness meditation. J Neurosci. 31: 5540-5548.

57. Hölzel BK, Ott U, Hempel H, Hackl A, Wolf K, Stark R, Vaitl D (2007): Differential engagement of anterior cingulate and adjacent medial frontal cortex in adept meditators and non-meditators. Neurosci Lett. 421: 16-21.

58. Grigg O, Grady CL (2010): Task-Related Effects on the Temporal and Spatial Dynamics of Resting-State Functional Connectivity in the Default Network. PLoS ONE. 5: e13311. 


\section{Figure Legend}

Figure 1. Baseline to Post-Treatment Resting State Functional Connectivity in the Mindfulness and Relaxation Training Groups. (A) Left dlPFC cluster (MNI: -22,52,10; $k=111, p<.05$ corrected). that showed increased rsFC with PCC from before to after mindfulness meditation training (HEM) relative to relaxation training (HER). Specifically, a time $\times$ condition spreading interaction analysis revealed a significant cluster in left dIPFC (panels A and B). A cluster in right dIPFC (MNI: 26,42,38; $k=24$ ) showed the same pattern of effects as the left dIPFC cluster but it did not survive correction, thus the (panel C) right dIPFC rsFC results should be interpreted with caution. .The spreading interaction effects that mediate IL- 6 effects are depicted for left (B) and right (C) dlPFC. Specifically, mean connectivity strength is shown for the mindfulness (HEM) and relaxation (HER) training groups at baseline and posttreatment. Error bars depict +/- 1 standard error.

Figure 2. IL-6 Mediation analyses. Increases in left dlPFC connectivity (MNI: $22,52,10$ ) significantly mediate (panel A) the time $\times$ treatment interaction on circulating (log transformed) IL-6. Increases in right dIPFC (MNI: 26,42,38) marginally significantly mediate (panel B) IL-6 effects. Numbers represent $b$ coefficients from mixed effect linear models, with parentheses representing $b$ coefficients when the main effect and time $\times$ treatment condition interaction terms and dIPFC connectivity parameter estimates are entered in a mixed effect linear model simultaneously. ${ }^{* * *} p<.05 ;{ }^{* *} p=.05 ;{ }^{*} \mathrm{p}=.06$ 
Table I. Baseline Characteristics of Randomized Participants.

\begin{tabular}{|l|c|c|c|}
\hline \multicolumn{1}{|c|}{ Characteristic } & HEM & HER & Difference Statistic \\
\hline Age [mean years (SD)] & $\begin{array}{c}37.94 \\
(10.96)\end{array}$ & $41.00(9.55)$ & $t(33)=-.48, p=0.64$ \\
\hline Gender & 11 & 9 & $\chi^{2}(1)=.24, p=0.63$ \\
\hline Male & 7 & 8 & \\
\hline Female & & & $\chi^{2}(5)=6.37, p=0.27$ \\
\hline Ethnicity & 10 & 13 & \\
\hline Caucasian & 6 & 2 & \\
\hline African American & 1 & 0 & \\
\hline Asian American & 0 & 1 & \\
\hline Latino(a) & 0 & 0 & \\
\hline Native American & 1 & 0 & \\
\hline Biracial & 0 & 1 & \\
\hline Other & $8.17(12.48)$ & $10.58(20.31)$ & $t(33)=-.43, p=0.67$ \\
\hline Months Unemployed & & & $\chi^{2}(8)=8.43, p=0.39$ \\
\hline Education & 1 & 0 & \\
\hline No high school degree & 1 & 0 & \\
\hline GED & 1 & 2 & \\
\hline High school degree & 3 & 2 & \\
\hline Technical training & 4 & 3 & \\
\hline Some college & 2 & 0 & \\
\hline Associate degree & 2 & 7 & \\
\hline Bachelor's degree & 3 & 3 & \\
\hline Master's degree & 1 & 0 & \\
\hline MD/PhD/JD/PharmD & 27.15 & $26.44(5.50)$ & $t(32)=.423, p=0.68$ \\
\hline Body Mass Index & $4.30)$ & & $t(32)=1.60, p=0.12$ \\
\hline Cognitive Impairment \\
(MMSE) & $29.39(.70)$ & $28.88(1.15)$ & \\
\hline IL-6 pg/mL & $1.81(2.03)$ & $1.21(.76)$ & $t .03, p=0.31$ \\
\hline Post-fMRI Days Elapsed & $5.06(3.29)$ & $5.29(4.52)$ & $t(32)=.17, \mathrm{p}=.86$ \\
\hline
\end{tabular}

Notes: Standard deviation values are provided in parentheses. HEM=3-Day Health Enhancement thru Mindfulness group; HER=3-Day Health Enhancement thru Relaxation group; MMSE= Mini-Mental State Exam; IL-6= Interleukin-6; Participants indicated their ethnicity/gender via self-report; Post-fMRI Days Elapsed= number of days elapsed at post-MRI session from the conclusion of the retreat program. 
Table 2. Circulating IL-6, by Treatment Group and Time

\begin{tabular}{|c|c|c|c|c|}
\hline & Mean HEM & $\underline{\mathrm{SE}}$ & Mean HER & $\underline{\mathrm{SE}}$ \\
\hline \multicolumn{5}{|l|}{ Log-Transformed IL-6 } \\
\hline Baseline & .13 & .07 & -.06 & .08 \\
\hline 4-Month Follow-Up & .08 & .08 & .08 & .07 \\
\hline \multicolumn{5}{|l|}{ Raw IL-6 } \\
\hline Baseline & 1.87 & .31 & 1.17 & .32 \\
\hline 4-Month Follow-Up & 1.45 & .32 & 1.41 & .30 \\
\hline
\end{tabular}

Notes: Means and Standard Errors (SE) from IL-6 MLMs, with Baseline Age as a covariate. IL-6= Circulating Interleukin-6; SE= standard error; HEM= Health Enhancement thru Mindfulness program; HER= Health Enhancement thru Relaxation program; All IL-6 values are in $\mathrm{pg} / \mathrm{mL}$. 


\section{Figure 1}

A)

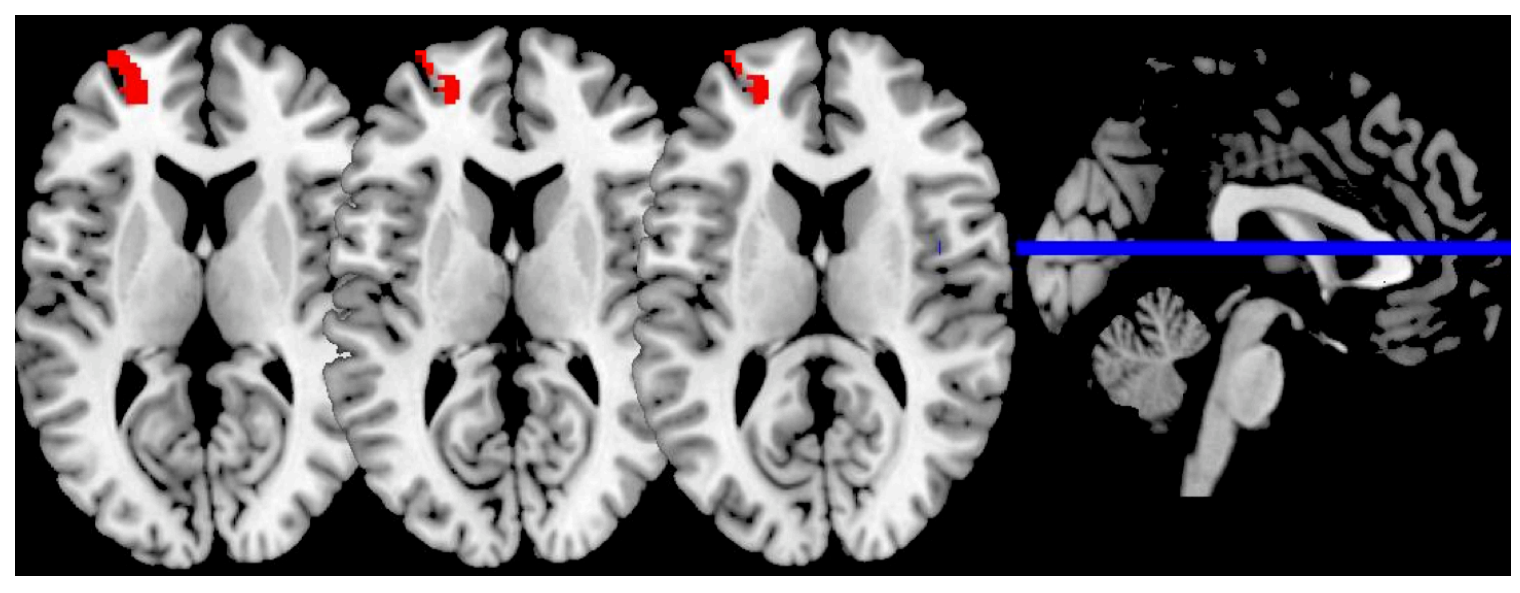

B) Left dIPFC (MNI: -22,52,10)

C) Right dIPFC (MNI:26,44,34)
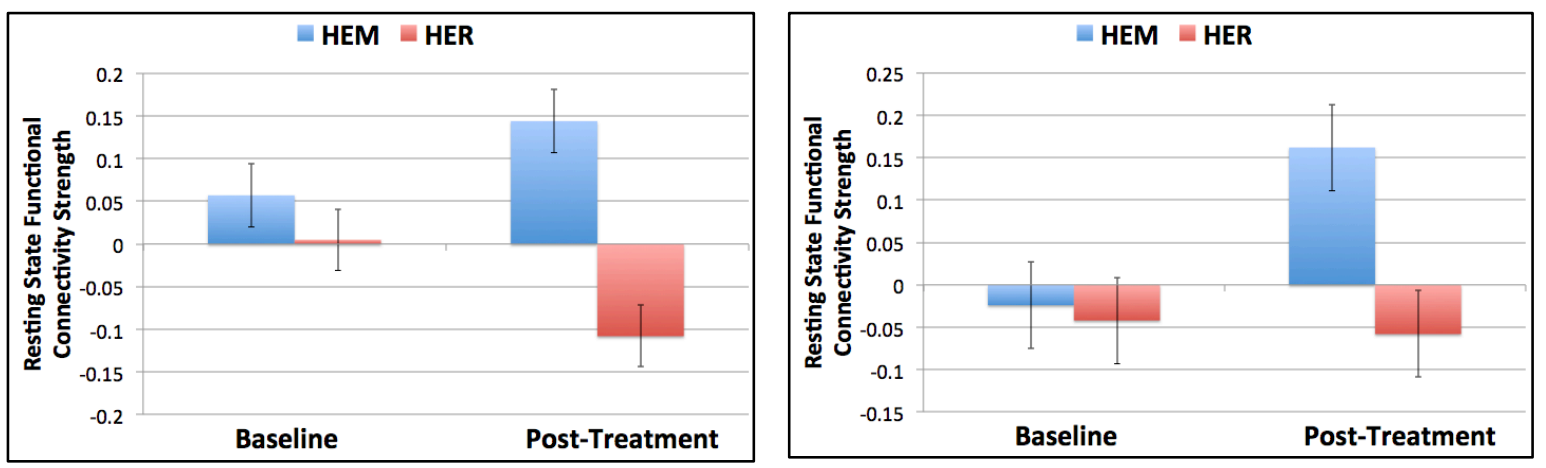


\section{Figure 2}

(A)



Path c': (.133)

(B)

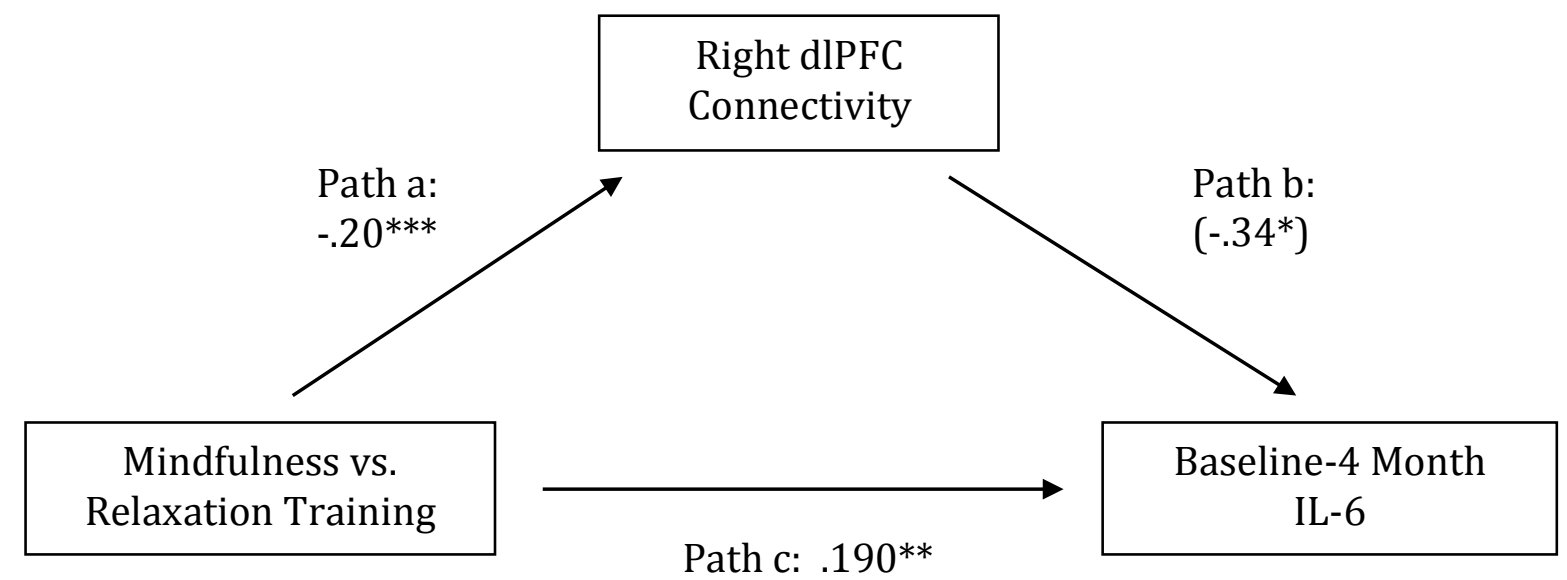

Path c': (.143) 


\section{Supplementary Online Information}

\section{Supplementary Text}

\section{Detailed Description of Mindfulness (HEM) and Relaxation (HER) Programs}

The present study utilizes two strategies for increasing the scientific rigor of meditation research. First, we have developed a 3-day condensed retreat format for teaching mindfulness meditation training entitled the Health Enhancement thru Mindfulness (HEM) program (which is based on exercises and didactics taught in the Mindfulness-Based Stress Reduction (MBSR) program). Delivery of the HEM program in a retreat format ensures a consistent and strong dose of mindful awareness practice across participants, provides a relatively controlled external environment away from the variety of stresses and supports of participants' lives, and has the potential to minimize drop-outs. Second, we have designed an active control or comparison program, Health Enhancement through Relaxation (HER) that is structurally similar to HEM, but avoids cultivation of mindfulness and body awareness. The use of a structurally-matched active comparison group helps to control for non-specific factors such as group support, teacher attention, physical activity, and mental engagement. Both HEM and HER consist of similar behavioral activities, scheduled on an hourly basis throughout each retreat day, such as sitting quietly, stretching, slow walking, eating, and discussion. However, the instructions and guidance for how to engage in the activities differ in systematic ways. In the HEM program, participants are instructed to train their attention and awareness to be fully present to each of these activities, learning the skill of mindful awareness. In contrast, HER participants engage in similar guided activities, but are instructed to participate in these activities in a relaxed and restful way, to let their minds wander, or even to rest or sleep.

Common features of the HEM and HER retreats included: individual 10 minute interviews with the teacher on Day 1 and Day 3 in order to build rapport and also assess progress, instructions to avoid discussion with members of the other group in order to avoid cross-contamination of groups, and instructions to keep up with practice. CD's with meditation (HEM group) or relaxation exercises (HER group) were provided for home use following the retreat.

HEM Program. The HEM retreat program was designed as an adapted and condensed version of the 8-week MBSR program. The specific content of the HEM program was developed in consultation with a senior teacher at the UMass Medical School's Center for Mindfulness (Melissa Blacker, MA). On retreat day 1, HEM participants were welcomed and introduced to the topic of mindfulness meditation for stress reduction, and oriented to the program. Following participant introductions, the group engaged in a mindful eating exercise, and the body scan meditation was introduced after a period of gentle stretching. Participants were encouraged to practice mindful awareness of eating during lunch. Sitting meditation, walking meditation, and mindful movement (gentle hatha yoga postures) were also introduced on retreat Day 1 . After each formal meditation 
period, participants engaged in discussion of their observations about themselves and the practices. During all interactions, from guided meditations to discussions, the instructor modeled and encouraged attitudes of mindfulness such as letting go of judgment and expectations, cultivating self-care, patience, and friendly curiosity regarding present moment experience. In the evening of Day 1, participants were asked to notice pleasant and unpleasant events and record their physical sensations, moods or emotions, and thoughts in their retreat notebook, to be discussed on Day 2. Participants were asked to continue their awareness practice by remaining relatively quiet after the group sessions ended at 9PM. During Day 2, which began at 7:30AM, formal mindfulness meditation practices were continued, consisting of mindful movement (yoga), sitting meditation, guided and unguided walking meditation, and meditation on various objects of attention, such as breath sensations, body sensations, sounds, moods or emotions, and thoughts and the spaces between thoughts. Discussions during Day 2 included exploration of pleasant and unpleasant events, stress and stress physiology, and reacting and responding to stress. The structure of these discussions included reflections in dyads or triads as well as the entire group. Participants were asked to remain quiet during the evening session until after breakfast on Day 3. The intention of the quiet period was to foster self-care and deepen the mindful awareness experienced during the day's group sessions. On retreat Day 3, formal meditation practices continued, with the addition of Choiceless Awareness and Lovingkindness or Metta meditation. Building from the previous day's discussions of stress reactivity and the possibility of responding to stress with greater flexibility and presence, Day 3 discussions focused more closely upon participants' own life challenges, and their plans for meeting their unemployment and job-seeking stress with mindfulness. Participants worked individually, in dyads, and with the entire group to develop their intentions for continuing their meditation practice and for applying what they had learned at the retreat to their daily lives. Closure exercises included yoga postures or favorite stretches taught by the group members, and sharing of good-byes.

HER Program. The HER program was designed to maximize similarity in activity to the HEM program but without mindfulness skill development. On Day 1, participants were oriented to the HER program as an opportunity to rest and rejuvenate and gain information about healthy living. They had the opportunity to introduce themselves to the group and to share their ways of managing stress. To parallel the HEM meditation without mindfulness or specific instructions about awareness of body sensations, the HER instructor led imagery exercises focused on visualizing a stream and later on a comfortable and safe place. To parallel the dyadic work in the HEM group, the HER participants worked in pairs to develop scripts for pleasant, relaxing place imagery, and guided one another in this relaxation exercise. Discussions throughout Day 1 and Day 2 included topics such as exercise for stress management, nutrition, using Michael Pollan's Food Rules, and Sleep Hygeine. To match the mindful yoga of the HEM group, HER participants engaged in stretches led using counting or joke-telling in order to avoid the development of body awareness and acceptance. On Day 2, HER retreatants continued to engage in light stretching, took walks, engaged in drawing and imagery exercises involving exploration of their own strengths and values. Stress and Health 
was a topic for discussion, with participants working in dyads as well as the whole group to explore what they experience when they are stressed. Hobbies and interests was an additional topic for discussion. On Day 3, HER participants continued gentle calisthenics and engaged in writing about what they were learning at the retreat. Discussions centered on stress and social support, and participants used drawing to explore their own social circles of support, and discussed this in dyads and the entire group. Imagery exercises included reflecting on the future and where participants imagined themselves being in five years. The group closed with creation of and sharing of personal plans for a healthy daily routine, and sharing of good-byes.

\section{Overview of Parent Study Measurement Approach}

The present report focuses on testing hypotheses about mindfulness training alterations in Default Mode Network (DMN) resting state functional connectivity (rsFC), and whether these training neural alterations prospectively predict changes in the health biomarker IL- 6 at follow-up. These neural and circulating IL-6 measures are part of a broader measurement battery in this study, the other measures we aim to describe in other published reports. Here we provide an overview of the additional measures collected in this study:

Baseline Assessment: psychosocial and individual difference self-report questionnaire packet (e.g., SF-36, Perceived Stress Scale, Life Experiences Survey, UCLA Loneliness).

Baseline MRI: 1 hour functional and structural neuroimaging session (high resolution structural scan, four functional scans: resting state BOLD, Multi-Source Interference Task, Affect labeling, and Unemployment Stress Task). At the end of the fMRI session participants completed an audio-guided mindfulness meditation task (during arterial spin labeling perfusion MRI).

Retreat Assessment: blood sample (pre-retreat prior to randomization), palm pilot assessments ( 5 times per day during all retreat days), instructor interviews (during Day 1 and during Day 3), and retreat behavioral tasks (e.g., walking speed, implicit tasks).

Post-Treatment MRI: [same measures as baseline MRI]

4-Month Follow-Up Assessment session at Retreat Center: blood sample, hair sample, psychosocial self-report questionnaire packet [same as at baseline, plus additional program/study evaluation measures, assessment of job status and jobseeking behaviors], behavioral task measures (implicit tasks). 
Table S1. Study inclusion/exclusion criteria. Participants were required to meet all study criteria at screening to be enrolled in the trial.

\begin{tabular}{|c|c|}
\hline \multicolumn{2}{|c|}{ General } \\
\hline $\begin{array}{ll}\text { Inclusion: } \\
\text { - } & 24-54 \text { years } \\
\text { - } & \text { Fluent in English } \\
\text { - Nonsmoker (smoking prohibited at } \\
\quad \text { retreat center) }\end{array}$ & $\begin{array}{ll}\text { Exclusion: } \\
\text { - } \\
\text { - } \\
\text { - Seriounitive impairment }(<23 \text { on MMSE) } \\
\text { - }>2 \mathrm{x} / \text { week) } \\
\text { drinkohol Consumption }(>15 \\
\text { - } \text { Recreational Drug Use (past month) } \\
\text { - Pregnancy or Breastfeeding } \\
\end{array}$ \\
\hline \multicolumn{2}{|c|}{ Health \& Immune-Related } \\
\hline $\begin{array}{l}\text { Exclusion: } \\
\text { - Hospitalization for mental or physical } \\
\text { health problem (past } 6 \text { months) } \\
\text { - Chronic disease (e.g., cancer, HIV, } \\
\text { diabetes, heart disease, arthritis) }\end{array}$ & $\begin{array}{ll}\quad \text { Medication use: } \\
\circ \quad \text { Mental health problems } \\
\circ \quad \text { Cholesterol-lowering meds } \\
& \text { (Crestor, statins) } \\
\circ & \text { Immune-related treatment } \\
& \text { (corticosteroids, chemotherapy, } \\
& \text { transplantation medication) }\end{array}$ \\
\hline \multicolumn{2}{|c|}{ fMRI Criteria } \\
\hline $\begin{array}{ll}\text { Exclusion: } \\
\text { - } \quad \text { Left-handed } \\
\text { - Presence of metal in body } \\
\text { - Weight }>350 \text { pounds }\end{array}$ & $\begin{array}{ll}\text { - } & \text { Claustrophobia } \\
\text { - } & \text { Neurological disorders (epilepsy, spina } \\
& \text { bifida, stroke, traumatic brain injury) }\end{array}$ \\
\hline \multicolumn{2}{|c|}{ Stress \& Unemployment } \\
\hline $\begin{array}{l}\text { Inclusion: } \\
\text { - } \quad \text { Unemployed (working <20 } \\
\text { hours/week) } \\
\text { - } \quad \text { Seeking employment } \\
\text { - } \quad \text { Having trouble finding a job } \\
\text { - Stressed: total score }>5 \text { on job-seeking } \\
\text { PSS (4 items listed at right) } \\
\quad \text { 5-point Likert scale }(0-\text { never to } 4 \\
\quad-\text { very often })\end{array}$ & $\begin{array}{l}\text { Adapted Job Seeking Stress Screening Items } \\
\text { 1. In the last month, how often have you felt that } \\
\text { you were unable to control the important things } \\
\text { in your life? } \\
\text { 2. In the last month, how often have you felt } \\
\text { confident about your ability to handle your job- } \\
\text { related problems? This could include your efforts } \\
\text { at finding a job, or paying your bills. (reverse } \\
\text { scored) } \\
\text { 3. In the last month, how often have you felt that } \\
\text { things were going your way in finding a job? } \\
\text { (reverse scored) } \\
\text { 4. In the last month, how often have you felt } \\
\text { difficulties were piling up so high that you could } \\
\text { not overcome them? }\end{array}$ \\
\hline
\end{tabular}


Table S2. Whole-brain analyses of regions displaying increased PCC-seeded resting state functional connectivity in the mindfulness relative to the relaxation treatment program in a spreading interaction analysis using contrast weights: [-1(pre,HEM), -1(pre,HER), 3(post, $H E M),-1$ (post,HER)] ( $(p<0.005, k>50)$. Specifically, regions that are more coupled with PCC after the HEM training (relative to HER training).

\begin{tabular}{|l|l|l|l|}
\hline Region & Cluster Size & Peak MNI Coordinates & $\boldsymbol{Z}$ \\
\hline Right Superior Frontal Gyrus & 147 & $2062-6$ & 3.97 \\
\hline Left Pallidum & 72 & $-20-42$ & 3.68 \\
\hline Left Insula & 57 & $-2618-8$ & 3.98 \\
\hline Left Pallidum & 62 & $-60-6$ & 4.09 \\
\hline Left Thalamus & 54 & $-28-268$ & 3.58 \\
\hline Left Middle Frontal Gyrus & 117 & -225210 & 3.44 \\
\hline Left Superior Frontal Gyrus & 79 & -304238 & 3.11 \\
\hline Right Supramarginal Gyrus & 66 & $60-4438$ & 3.35 \\
\hline
\end{tabular}


Table S3. Whole-brain analyses of regions displaying decreased PCC-seeded resting state functional connectivity in the mindfulness relative to the relaxation treatment program in a spreading interaction analysis using contrast weights: [1(pre,HEM), 1(pre,HER), -3(post, HEM), 1(post,HER)] ( $(p<0.005, k>50)$. Specifically, regions that are less coupled with PCC after the HEM training (relative to HER training).

\begin{tabular}{|l|l|l|l|}
\hline Region & Cluster Size & Peak MNI Coordinates & $Z$ \\
\hline Right Inferior Temporal Cortex & 54 & $462-44$ & 3.23 \\
\hline Right Fusiform Gyrus & 56 & $36-62-14$ & 3.96 \\
\hline Left Lingual Gyrus & 353 & $-12-78-4$ & 4.09 \\
\hline Left Inferior Frontal Gyrus & 55 & -46320 & 3.33 \\
\hline Right Insula & 57 & $32-2620$ & 3.57 \\
\hline Right Postcentral Gyrus & 235 & $48-428$ & 4.55 \\
\hline Left Precentral Gyrus & 91 & $-52-1236$ & 3.34 \\
\hline Right Paracentral Lobule & 82 & $4-3464$ & 3.43 \\
\hline Right Precentral Gyrus & 464 & $10-680$ & 4.36 \\
\hline
\end{tabular}




\section{Table S4. A detailed overview of the 3-day Health Enhancement thru Mindfulness (HEM) and Health Enhancement thru Relaxation (HER) intervention programs.}

\begin{tabular}{|c|c|c|c|}
\hline & Health Enhancement thru Mindfulness & & Health Enhancement thru Relaxation \\
\hline $\begin{array}{l}\text { Day } 1 \\
10- \\
12: 15 \\
\text { chapel }\end{array}$ & $\begin{array}{l}\text { Welcome and orientation to the } \\
\text { guidelines for participation in the } \\
\text { program; introduce the concept of } \\
\text { mindfulness; centering exercise and } \\
\text { individual introductions; mindful raisin- } \\
\text { eating exercise; } 45 \text {-minute body scan } \\
\text { exercise (show alternative postures, and } \\
\text { start with some stretching). } \\
\text { Depending on when program starts, } \\
\text { raisin and body scan may be after lunch. }\end{array}$ & $\begin{array}{l}\text { 10:00- } \\
\text { 12:00 } \\
\text { Conf area }\end{array}$ & $\begin{array}{l}\text { Orientation, guidelines*, and introductions } \\
\text { (pairs first, then big group) } \\
\text { How do you manage stress? (keep it somewhat } \\
\text { light) (this may generate a list of diverse coping } \\
\text { methods, and can be referred back to as the } \\
\text { weekend goes on). } \\
\text { End session with stream imagery for relaxation. }\end{array}$ \\
\hline $\begin{array}{l}12: 15- \\
1: 45\end{array}$ & $\begin{array}{l}\text { Mindful lunch (not silent) }(1 / 2 \mathrm{hr} \text { in } \\
\text { cafeteria, } 1 \mathrm{hr} \text { break) ( } 3 \text { student } \\
\text { interviews) }\end{array}$ & $12: 00-1: 30$ & Lunch (3 student interviews) \\
\hline $\begin{array}{l}1: 45- \\
3: 15 \\
\text { Conf } \\
\text { area }\end{array}$ & $\begin{array}{l}\text { Continue intros, raisin exercise, body } \\
\text { scan as needed, depending on progress } \\
\text { prior to lunch. } \\
\text { Discussion of body scan/morning, weave } \\
\text { in relevant 'attitudes of mindfulness' } \\
\text { (non-striving, patience, don't know } \\
\text { mind) intro to sitting and postures, } \\
\text { sitting meditation with AOB. Review } \\
\text { definitions of mindfulness as indicated. } \\
\text { Use Mountain meditation or other } \\
\text { stabilizing imagery as indicated. }\end{array}$ & $\begin{array}{l}\text { 1:30-3:00 } \\
\text { chapel }\end{array}$ & $\begin{array}{l}\text { Brief disc of physical activity as method for } \\
\text { stress reduction. } \\
\text { Stretching / exercise. } \\
\text { Discussion what keeps you from exercising, if } \\
\text { you don't--list }\end{array}$ \\
\hline $\begin{array}{l}3: 15- \\
4: 15\end{array}$ & Snack /tea (2 student interviews) & $3: 00-4: 00$ & Snack / tea (2 student interviews) \\
\hline $\begin{array}{l}4: 15- \\
5: 45 \\
\text { Chapel }\end{array}$ & $\begin{array}{l}\text { Standing and walking } \\
\text { Mindful movement yoga, Intro } \\
\text { awareness of pleasant events assignment } \\
\text { (to discuss tomorrow) }\end{array}$ & $\begin{array}{l}\text { 4:00-5:30 } \\
\text { Conf area }\end{array}$ & $\begin{array}{l}\text { Intro to safe place. } \\
\text { Demonstration of dyadic work--development of } \\
\text { an image of being safe and at ease. Work in } \\
\text { pairs, writing down, then guiding each other. } \\
\text { (comfort and ease imagery) } \\
\text { Share feedback in large group }\end{array}$ \\
\hline $\begin{array}{l}5: 45- \\
7: 30\end{array}$ & Mindful dinner (2 student interviews) & $5: 30-7: 30$ & Dinner (2 student interviews) \\
\hline $\begin{array}{l}7: 30-9 \\
\text { Conf } \\
\text { area }\end{array}$ & $\begin{array}{l}\text { Sit }(\sim 15 \mathrm{~min}) \text {. Walking. Seated body } \\
\text { scan, followed by stretching. Use } \\
\text { Mountain imagery as indicated. } \\
\text { Reflection and discussion of } 1 \text { st today’s } \\
\text { experiences, integrating attitudes of }\end{array}$ & $\begin{array}{l}7: 30-9 \\
\text { chapel }\end{array}$ & $\begin{array}{l}\text { Sleep Hygiene: talk about the connection } \\
\text { between sleep and health. } \\
\text { Ask them how they sleep (this could take a long } \\
\text { time!) } \\
\text { Give Sleep Hygiene handout and go over it }\end{array}$ \\
\hline
\end{tabular}




\begin{tabular}{|c|c|c|c|}
\hline & $\begin{array}{l}\text { mindfulness. } \\
\text { Orientation and instructions for } \\
\text { continuing mindfulness practice during } \\
\text { the later evening and bedtime, noting } \\
\text { pleasant and also unpleasant events, } \\
\text { (give calendars) returning wandering } \\
\text { mind to present moment awareness. } \\
\text { Lying down Body Scan. }\end{array}$ & & $\begin{array}{l}\text { briefly. } \\
\text { Nutrition (using Pollen material) } \\
\text { What is true; what is helpful here? } \\
\text { Reminder: maintain quiet this evening and in } \\
\text { early morning (if you talk, keep it fairly quiet) } \\
\text { Relaxation exercise for sleep. }\end{array}$ \\
\hline \begin{tabular}{|l|}
$9-$ \\
$10: 30$
\end{tabular} & Quiet time (4-5 interviews) & $9: 00-10: 30$ & Quiet time (4-5 interviews) \\
\hline \begin{tabular}{|l|}
$10: 30$ \\
pm
\end{tabular} & Lights out & $10: 30 \mathrm{pm}$ & Lights out \\
\hline $\begin{array}{l}\text { Day } 2 \\
7 \text { am } \\
\end{array}$ & Wake up (maintain silence) & $\begin{array}{l}\text { Day } 2 \\
\text { 7am }\end{array}$ & Wake up (maintain quiet) \\
\hline $\begin{array}{l}7: 30- \\
8: 15 \\
\text { Chapel }\end{array}$ & $\begin{array}{l}\text { Mindful stretch - on floor, followed by } \\
\text { sit with AOB, AO body sensations. Prep } \\
\text { for mindful breakfast. }\end{array}$ & $\begin{array}{l}\text { 7:30-8:30 } \\
\text { Conf. }\end{array}$ & $\begin{array}{l}\text { Movement - gentle calesthenics } \\
\text { Reflective writing re: ideas sparked by } \\
\text { yesterday's and last night's disc (what do they } \\
\text { want to explore, what do they want to } \\
\text { remember.) }\end{array}$ \\
\hline $\begin{array}{l}8: 15- \\
9: 15\end{array}$ & Mindful Breakfast (silence optional) & $8: 30-9: 30$ & Breakfast \\
\hline $\begin{array}{l}9: 15- \\
10: 45 \\
\text { Conf } \\
\text { area }\end{array}$ & $\begin{array}{l}\text { Brief sit ( } \sim 15 \text { minutes). Discussion of } \\
\text { last evening and this morning's } \\
\text { mindfulness practice, including silence; } \\
\text { dyads and then group disc/ mindful } \\
\text { listening re: pleasant and unpleasant } \\
\text { events. Begin disc of what makes an } \\
\text { event pleasant/ unpleasant; topic of } \\
\text { 'stress/ stress physiology' } \\
\end{array}$ & $\begin{array}{l}\text { 9:30-11 } \\
\text { Chapel }\end{array}$ & $\begin{array}{l}\text { Physical Exercise } \\
\text { 'non-mindfulness' version of yoga } \\
\text { stretch/strengthening exercises. } \\
\text { Incorporate some HEP exercise activities. } \\
\text { Something to think about on your walk: what } \\
\text { are your personal strengths? }\end{array}$ \\
\hline $\begin{array}{l}10: 45- \\
11: 15\end{array}$ & Walking meditation (unguided) & 11-11:30 & Take a walk \\
\hline $\begin{array}{l}11: 15- \\
12 \\
\text { Conf } \\
\text { area }\end{array}$ & $\begin{array}{l}\text { Mindful stretch followed by sit. } \\
\text { Continue disc of anatomy of stress, stress } \\
\text { reactivity /automatic pilot and possibility } \\
\text { of responding mindfully to stressful } \\
\text { events. Use metaphors as indicated (e.g, } \\
4 \text { story building, waterfall and barrel, } \\
\text { etc.) }\end{array}$ & $\begin{array}{l}11: 30- \\
12: 15 \\
\text { Chapel }\end{array}$ & $\begin{array}{l}\text { Discussion of strengths and values. Who are } \\
\text { your role models and what do you admire re: } \\
\text { them? } \\
\text { Exercise: draw your personal 'values and } \\
\text { strengths' coat of arms. Share 'coat of arms' in } \\
\text { dyads and then large groups. }\end{array}$ \\
\hline $12-1$ & Mindful lunch & $12: 15-1: 15$ & Lunch \\
\hline $\begin{array}{l}1-2: 30 \\
\text { Chapel }\end{array}$ & $\begin{array}{l}\text { Sit with AOB, Body, AOSound, AO } \\
\text { Thought (internal image/talk). Disc of } \\
\text { participants own stress reactivity patterns } \\
\text { (start with dyads) how do they know }\end{array}$ & $\begin{array}{l}1: 15-3 \\
\text { Conf area }\end{array}$ & $\begin{array}{l}\text { Demonstration of development of imagery for } \\
\text { feeling competent and effective, or strong. } \\
\text { They break into dyads to do this. } \\
\text { (if you don't have a memory to use, can }\end{array}$ \\
\hline
\end{tabular}




\begin{tabular}{|c|c|c|c|}
\hline & $\begin{array}{l}\text { they are stressed and how do they take } \\
\text { care of self. Disc mindful approach to } \\
\text { emotions; problem focused and emotion } \\
\text { focused coping. Lovingkindness } \\
\text { meditation if appropriate. Introduce } \\
\text { possibility of silent period (to start } \\
\sim 4: 30 \mathrm{pm} \text { ). }\end{array}$ & & $\begin{array}{l}\text { imagine one - like you are an actor in a scene) } \\
\text { Share feedback in large group }\end{array}$ \\
\hline $\begin{array}{l}2: 30- \\
3: 30\end{array}$ & Snack / tea & $3-4$ & Snack / tea \\
\hline $\begin{array}{l}3: 30- \\
5: 30 \\
\text { Conf } \\
\text { area }\end{array}$ & $\begin{array}{l}\text { Chair yoga followed by sit. Continue } \\
\text { discussion of stress reactivity and } \\
\text { mindful responding as needed. Disc of } \\
\text { upcoming silent time with rationale as a } \\
\text { time to be with yourself, focus on } \\
\text { yourself in a caring way. If } \\
\text { group/individuals seem able to meet this, } \\
\text { silence begins ( } 4: 30 \mathrm{pm}) \text { run this } \\
\text { section like MBSR retreat: body scan, } \\
\text { mindful movement, sitting, } \\
\text { lovingkindness meditation (include } \\
\text { choiceless awareness) }\end{array}$ & $\begin{array}{l}4-5: 45 \\
\text { Chapel }\end{array}$ & $\begin{array}{l}\text { Stress physiology } \\
\text { Stress and Health: JKZ handout, } \\
\text { Charting arousal/time and symptom } \\
\text { development—-the arousal curve and what } \\
\text { symptoms shows up at which level of arousal. } \\
\text { Do this as a group discussion. What do they } \\
\text { experience when they are stressed.. } \\
\text { Do this in dyads first, and then expand to the } \\
\text { bigger group. This should take approximately } 1 \\
\text { hour. } \\
\text { Go back to Pollen material if did not finish it } \\
\text { yesterday. } \\
\text { Earlier today we did imagery exercises around } \\
\text { our strengths. What personal strengths do you } \\
\text { have? } \\
\text { Hobbies and interests - have a go around about } \\
\text { favorite hobbies and interests that help them to } \\
\text { feel comfortable / good. Create a group list of } \\
\text { ideas. }\end{array}$ \\
\hline $\begin{array}{l}5: 30- \\
7: 15\end{array}$ & Dinner & $\begin{array}{l}5: 45- \\
7: 30 \mathrm{pm}\end{array}$ & Dinner \\
\hline $\begin{array}{l}7: 15-9 \\
\text { Chapel }\end{array}$ & $\begin{array}{l}\text { Practice in silence. Variety of formal } \\
\text { practices, include choiceless awareness. } \\
\text { Poetry reading. Mountain or Lake } \\
\text { meditations as indicated. }\end{array}$ & $\begin{array}{l}7: 30-9 \\
\text { Conf area }\end{array}$ & $\begin{array}{l}\text { Disc - how do I have / make fun? } \\
\text { Demonstration and then guided imagery for fun, } \\
\text { breaking into dyads to develop them. } \\
\text { Humorous video }\end{array}$ \\
\hline $\begin{array}{l}9- \\
10: 30\end{array}$ & Quiet time & $9-10: 30$ & Quiet time \\
\hline $10: 30$ & Lights out & $10: 30$ & Lights out \\
\hline $\begin{array}{l}\text { Day } 3 \\
7 \text { am }\end{array}$ & Wake up & $\begin{array}{l}\text { Day } 3 \\
\text { 7am }\end{array}$ & Wake up \\
\hline $\begin{array}{l}7: 30- \\
8: 15\end{array}$ & $\begin{array}{l}\text { Mindful stretching/yoga followed by } \\
\text { brief body scan. }\end{array}$ & $\begin{array}{l}7: 30-8: 30 \\
\text { chapel }\end{array}$ & $\begin{array}{l}\text { Movement - gentle calesthenics - narrative } \\
\text { writing - free association or free drawing }\end{array}$ \\
\hline
\end{tabular}




\begin{tabular}{|c|c|c|c|}
\hline $\begin{array}{l}\text { Conf } \\
\text { area }\end{array}$ & & & What am I learning/ do I want to take with me? \\
\hline $\begin{array}{l}8: 15- \\
9: 15\end{array}$ & Mindful breakfast (silence) & $8: 30-9: 30$ & Breakfast \\
\hline $\begin{array}{l}9: 15- \\
10 \\
\text { chapel }\end{array}$ & $\begin{array}{l}\text { Continue formal practices (guided). } \\
\text { Seeing meditation. Participants remain in } \\
\text { silence. }\end{array}$ & $\begin{array}{l}9: 30-10: 30 \\
\text { Conf area }\end{array}$ & $\begin{array}{l}\text { Disc of stress and social support. Support can } \\
\text { come from the living or the deceased. Even just } \\
\text { a small thing from memory can be powerful } \\
\text { (Nazi example) } \\
\text { Draw circles of intimacy/ mandala of social } \\
\text { support system }\end{array}$ \\
\hline $10-11$ & $\begin{array}{l}\text { Walking unguided. Mindfulness in } \\
\text { motion (3 interviews) }\end{array}$ & $\begin{array}{l}10: 30- \\
11: 30\end{array}$ & Quiet Rest or take a walk (3 interviews) \\
\hline $\begin{array}{l}11-12 \\
\text { chapel }\end{array}$ & $\begin{array}{l}\text { Sit. Awareness Exercises for breaking } \\
\text { silence (dyads, etc). Group discussion of } \\
\text { silence. If we have not engaged in } \\
\text { silence, continue discussion of mindful } \\
\text { approaches for self care and responding } \\
\text { to stress. }\end{array}$ & $\begin{array}{l}11: 30- \\
12: 15 \\
\text { Conf area }\end{array}$ & $\begin{array}{l}\text { Discussion of support system /mandalas in } \\
\text { dyads and in big group. Brief relaxation } \\
\text { focusing on feeling competent and connected, } \\
\text { Supported. }\end{array}$ \\
\hline $\begin{array}{l}12- \\
1: 30\end{array}$ & $\begin{array}{l}\text { Mindful Lunch (optional silence) (3 } \\
\text { interviews) }\end{array}$ & $12: 15-2: 00$ & Lunch (3 interviews) \\
\hline $\begin{array}{l}1: 30-3 \\
\text { Conf } \\
\text { area }\end{array}$ & $\begin{array}{l}\text { Continue formal practices. Include } \\
\text { Mountain meditation as well as other } \\
\text { formal practices already introduced. } \\
\text { Mindfulness in everyday life disc. } \\
\text { Obstacles to applying what you have } \\
\text { learned and how you are going to work } \\
\text { with them. Formal practice - body scan. } \\
\text { Development of personal 'action plans' }\end{array}$ & $\begin{array}{l}\text { 2:00-3:30 } \\
\text { Chapel }\end{array}$ & $\begin{array}{l}\text { Obstacles to applying who you have learned and } \\
\text { how you are going to work with them } \\
\text { Guided reflections for the future - where do you } \\
\text { imagine yourself } 5 \text { years from now? Who is } \\
\text { there? What are you doing? } \\
\text { Discuss in small and large groups }\end{array}$ \\
\hline $3-3: 45$ & Break / tea (2 interviews) & $3: 30-4: 15$ & Break / tea (2 interviews) \\
\hline $\begin{array}{l}3: 45- \\
5: 30 \\
\text { chapel }\end{array}$ & $\begin{array}{l}\text { Practice. group led yoga stretches if } \\
\text { appropriate. Discussion of personal plans } \\
\text { for continuing practice. Final comments } \\
\text { and closure exercises. Dyads and whole } \\
\text { group. }\end{array}$ & $\begin{array}{l}\text { 4:15-5:30 } \\
\text { Conf area }\end{array}$ & $\begin{array}{l}\text { Making a personal plan for your self: creation of } \\
\text { daily routine, relaxation, etc. Final } \\
\text { comments/closing exercises. } \\
\text { Drawing - this group and this time here. }\end{array}$ \\
\hline $\begin{array}{l}5: 30- \\
7: 30\end{array}$ & Final study procedures (5 interviews) & $5: 30-7: 30$ & Final study procedures (5 interviews) \\
\hline
\end{tabular}


Figure S1. Consort Flowchart

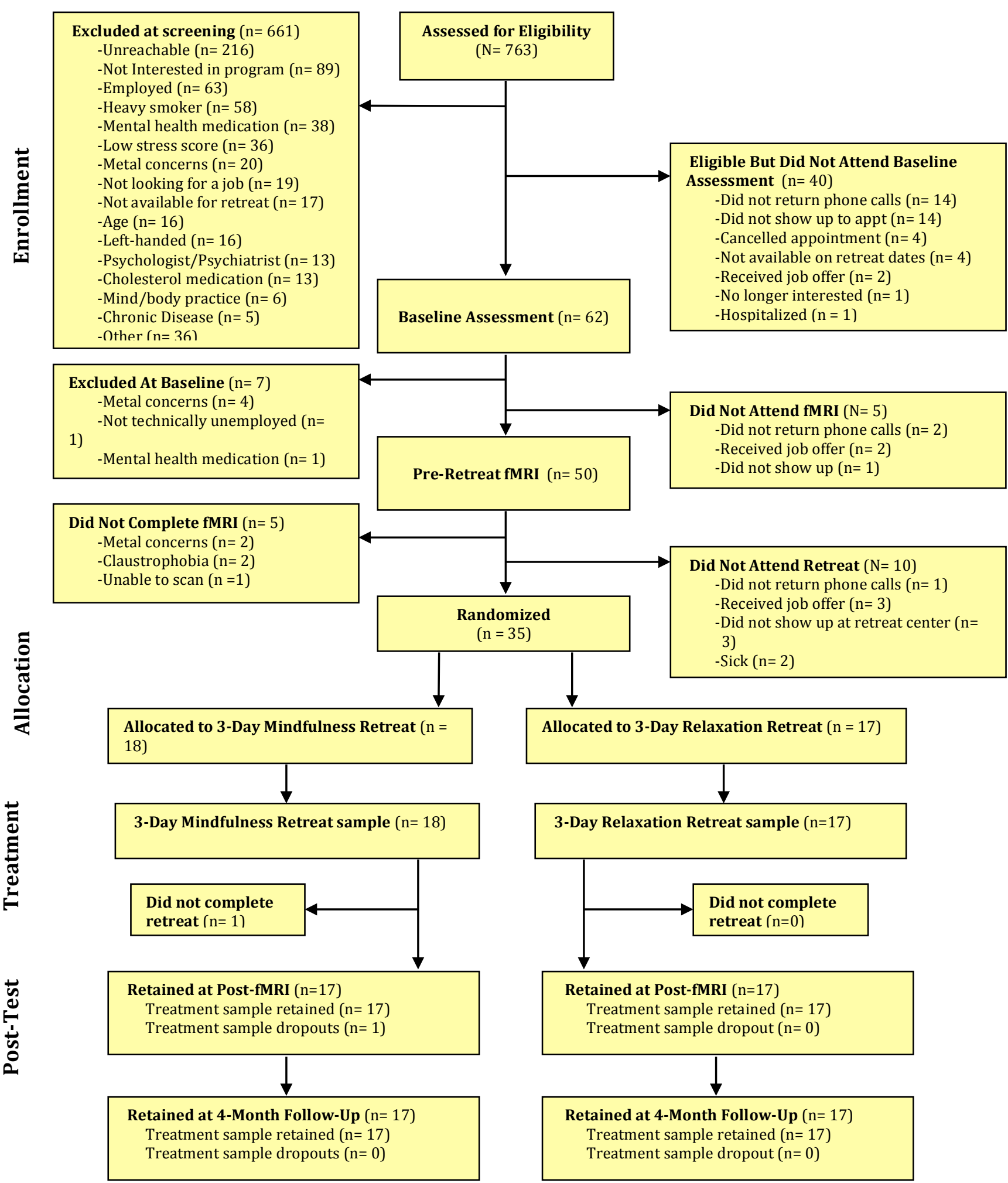

